\title{
Implementation of a structured patient handoff between health care providers at a private facility in the Autonomous City of Buenos Aires
}

\author{
Cristian García Roig, M.D. ${ }^{a}$, María V. Viard, M.D. ${ }^{a}$, Ezequiel García Elorrio, M.D. ${ }^{b}$, \\ Inés Suárez Anzorena, M.D. ${ }^{b}$ and Facundo Jorro Barón, M.D. ${ }^{b}$ \\ Collaborators: Cecilia Veloso, B.S. ${ }^{a}$ and Clara García Gibson, M.D.
}

\begin{abstract}
Introduction. Failures in communication are common during patient handoffs between physicians, which predisposes to errors. Few articles have been published on this topic in Argentina. For this reason, our objective was to confirm whether using a structured handoff (I-PASS), which has been successfully used in the USA by DoctorStarmer, may reduce the omission of key data without prolonging its duration at
\end{abstract} our department.

Population and methods. The study was conducted at a private facility in the Autonomous City of Buenos Aires between June $15^{\text {th }}, 2017$ and March $31^{\text {st }}, 2018$. It had a quasi-experimental, uncontrolled, before-and-after design. Pre- and post-intervention handoffs were assessed. The intervention included training physicians on how to use a structured handoff mnemonic (I-PASS: illness severity, patient summary, action list, situation awareness and contingency planning, synthesis by receiver), training on team work, written computerized handoff document, feedback observations, and simulation.

Results. A total of 158 and 124 pre- and postintervention assessments were done respectively. The pre- and post-intervention comparison showed a significant improvement in most of the handoff key points. The time used for the handoff was 199 seconds (174-225) before the intervention and 210 seconds (190-230) after the intervention, $p=0.523$; interruptions also decreased significantly.

a. Sanatorio Mater Dei, Buenos Aires, Argentina.

b. Institute for Clinical and Health Care Effectiveness (Instituto de Efectividad Clínica y Sanitaria, IECS).

E-mail address:

Cristian García Roig, M.D.: garciaroig@gmail.com

Funding:

None.

Conclusion. Introducing the I-PASS program reduced key data omission without prolonging handoffs. Interruptions were also reduced.

Key words: patient handoff, patient safety, communication.

http: / / dx.doi.org/10.5546/ aap.2020.eng.e234

To cite: García Roig C, Viard MV, García Elorrio E, Suárez Anzorena I, Jorro Barón F. Implementation of a structured patient handoff between health care providers at a private facility in the Autonomous City of Buenos Aires. Arch Argent Pediatr 2020; 118(3):e234-e240.

\section{INTRODUCTION}

Communication is not a unidirectional phenomenon (from the sender to the receiver) but an interactive process in a context, with reactions in and from both participants. Human communication includes three interdependent areas: syntax (how information is conveyed), semantics (meaning), and pragmatics (the effect on behavior). ${ }^{1}$ Errors may occur in one or more areas. An inadequate context (distractions, interruptions) promotes the potential for errors.

Failures in communication, including critical data omission and transfer of misinformation, are common during handoffs between physicians. In addition, since the length of shifts at some emergency departments has been reduced, the number of handoffs between physicians has increased..$^{2,3}$ This situation entails a greater risk for errors in communication.

According to The Joint Commission (TJC) in the United States, two out of three sentinel events, i.e., those causing a severe injury or death, result from communication problems. In more than half of cases, errors take place during patient handoffs. For this reason, since 2006, TJC has advocated to standardize communication during handoffs..$^{4,5}$ That year, a national survey conducted in the United States revealed the scarcity of both structured handoffs and formal training on this topic among residents. ${ }^{6}$

Consistent with such advocacy, Starmer et al., created a structured hand off based on the I-PASS 
mnemonic. This way, they managed to include key, standardized data in both the written handoff document and the verbal handoff based on this mnemonic. Their project also included providing training on communication strategies and considering a protected setting to avoid distractions. As shown in their work, the implementation of this tool, known as the I-PASS bundle, helped to reduce medical errors by $23 \%$ and the rate of preventable adverse events

FIGURE 1. Quality assessment tool for patient handoffs and transfers

Assessment (underline as applicable):
Handoff (verbal) in the area: ER PEDIATRIC WARD
Transfer (written document)-ci) FROM ER TO PEDIATRIC WARD
FROM ER TO PICU
Did you use the handoff form?:
Time:
Date:
Patient identification with first and last names plus at least 1 indicator (age, date of birth, medical record number,
Yo number):
Was there any distraction or interruption during the handoff (phone calls, comersation about something not
related to the handoff, people not involved in the handoff entering the area)?

\begin{tabular}{|c|c|c|c|c|}
\hline \multicolumn{2}{|c|}{ l: Illness severity } & \multirow{2}{*}{$\begin{array}{c}\text { YES } \\
\text { o }\end{array}$} & \multirow{2}{*}{$\begin{array}{l}\text { NO } \\
\square\end{array}$} & \multirow{2}{*}{$\begin{array}{l}\text { NA } \\
\square\end{array}$} \\
\hline 1. & Patient's severity is discussed & & & \\
\hline \multicolumn{5}{|c|}{ P: Patient summary (the following is discussed) } \\
\hline 1. & Diagnosis & o & 0 & 0 \\
\hline 2. & Background of current condition & $\mathrm{a}$ & a & a \\
\hline 3. & History & 0 & 0 & 0 \\
\hline 4. & Critical events, complications & $\mathrm{c}$ & a & a \\
\hline 5 . & Lines, drainages, tubes, other devices & o & 0 & 0 \\
\hline 6. & Current status & 0 & 0 & o \\
\hline 7. & Most recent clinical examinations & 口 & a & a \\
\hline 8. & Medication list & 0 & 0 & 0 \\
\hline 9. & Date of admission & 0 & 0 & 0 \\
\hline \multicolumn{2}{|c|}{ A: Actions required during shift } & & & \\
\hline 1. & The behaviors to be followed are indicated. & o & a & a \\
\hline 2. & $\begin{array}{l}\text { The parties responsible for such behaviors are explicitly } \\
\text { indicated. }\end{array}$ & $\mathrm{a}$ & a & a \\
\hline \multicolumn{2}{|c|}{ S: Situation to be monitored } & & & \\
\hline 1. & Contingency planning is explained. & 0 & 0 & 0 \\
\hline 2. & The actions required for contingency are indicated. & a & a & o \\
\hline \multicolumn{2}{|c|}{ S: Synthesis by receiving physician } & & & \\
\hline 1. & $\begin{array}{l}\text { The receiving physician provides an adequate synthesis } \\
\text { of the patient. }\end{array}$ & $\mathrm{o}$ & 0 & 0 \\
\hline
\end{tabular}

1. Transfers will only be assessed if corresponding to patients admitted to the Emergency Department before the transfer to a ward/PICU, NOT in the case of patients transferred from another facility directly to the ward/PICU.

2. NA: not applicable; it means that the patient does not require the assessment of this item (e.g., a patient who is not on an analgesic regimen because their condition does not require it or who did not undergo any diagnostic test during the previous shift). 
by $30 \%$, without prolonging handoff duration. ${ }^{7,8}$

To date, in Argentina, there is a lack of studies assessing handoff improvement programs. Considering our medical communication problem and the good results obtained by Starmer, we decided to implement the I-PASS structured handoff at our Unit of Clinical Pediatrics of a private facility located in the Autonomous City of Buenos Aires (CABA).

Our objective was to determine whether introducing a structured patient handoff at our unit resulted in a reduced key data omission in the handoff document, an improved verbal handoff, and fewer interruptions and distractions, with no changes in duration.

\section{METHODS}

The study was conducted at the Division of Clinical Pediatrics of a private facility between June $15^{\text {th }}, 2017$ and March 31 ${ }^{\text {st }}, 2018$. The Pediatric Unit had 20 beds. Every day, three physicians worked from 8 a.m. to 2 p.m.; two, from 2 p.m. to 8 p.m.; and one, from 8 p.m. to 8 a.m. Patient handoffs took place at 8 a.m., 2 p.m., and 8 p.m. every day of the week. Handoff was done in a room exclusive for the unit's physicians.

The study had a quasi-experimental, uncontrolled, before-and-after design, and was carried out in two phases. Measures were obtained at baseline (first stage), from 6/15/2017 to $8 / 7 / 2017$ and after the intervention (second

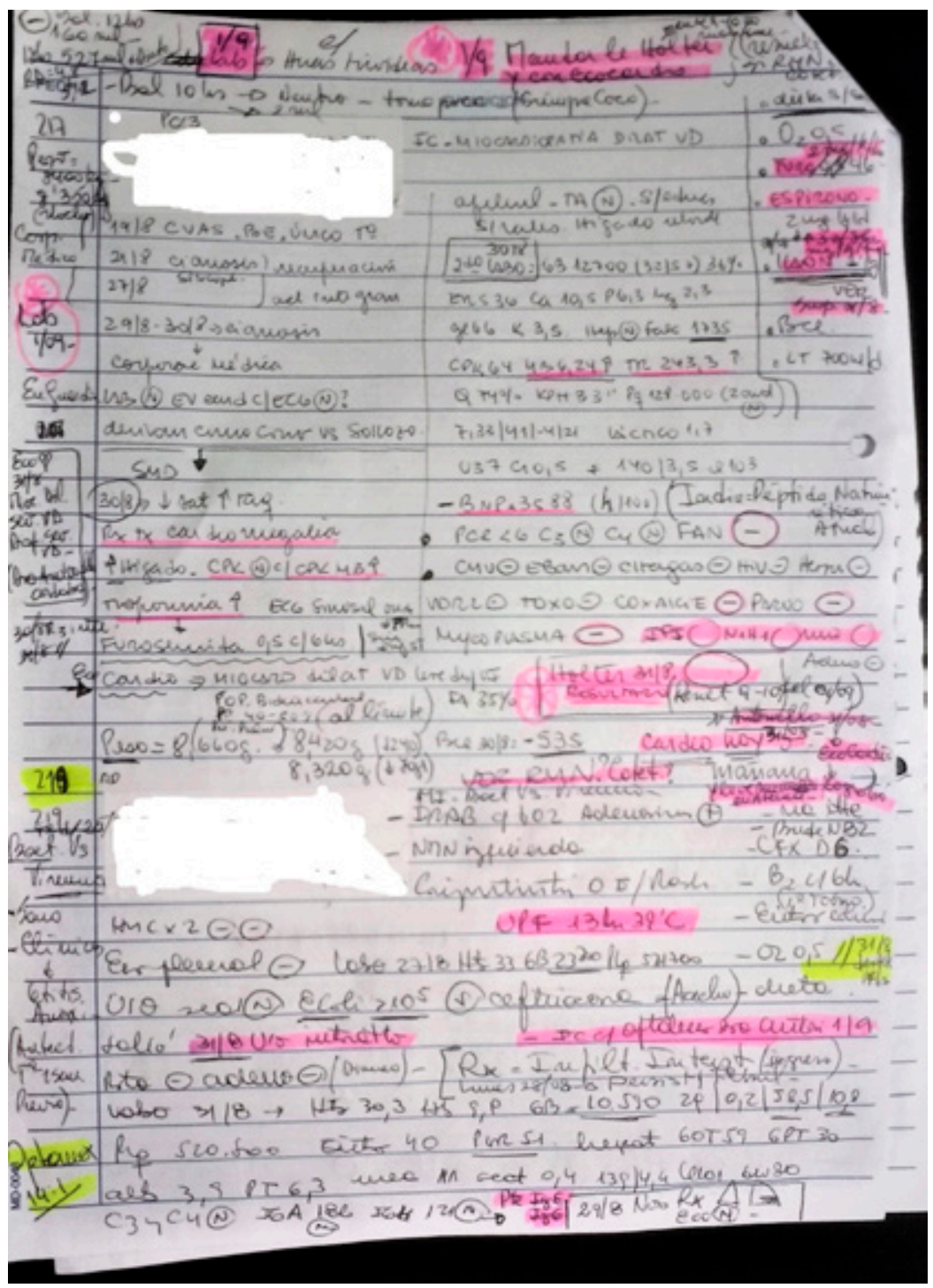


stage), from $8 / 8 / 2017$ to $3 / 31 / 2018$.

Before the intervention, the verbal and written handoffs were observed without interfering. A verification tool consisting of 15 key points was used during the observation. The tool originally implemented in the I-PASS study was translated and assessed for its approval by Starmer. The form was used to determine whether the verbal and written handoffs covered all the aspects considered by I-PASS, in addition to an adequate patient identification, the presence of distractions or interruptions, and the duration of each handoff (Figure 1).

Three handoffs were observed per day for a week, every 15 days, over a period of 2 months. Each scheduled handoff was observed during the entire week. Here we attach a picture of a written handoff before the intervention (Figure 2).

The intervention consisted in providing training on the I-PASS mnemonic, which included five steps: $I$ considered the illness severity; $P$ referred to the patient summary, including any current problem and the plans to manage it; $A$ provided a list of actions that the sender intended the receiver to do during their shift; the first $S$ was related to any situation and contingency that may occur; and the second $S$ referred to the synthesis made by the receiver of what they had understood. In addition, an introductory workshop, a grand round at the facility, role playing simulations with I-PASS, a written computerized handoff document for improvement purposes, and an advertising campaign (visible posters and a video on the five I-PASS key points) were carried out, and feedback was provided to improve the handoff process. Measures to prevent interruptions or distractions were taken, such as not using the phone during the handoff and signs indicating that the process should not be interrupted (Figure 3). Part of the training was guided by Doctor Starmer, the principal investigator of the I-PASS project in the United States.

The following items were considered key for assessment, based on the observation tool (Figure 1):

Adequate patient identification: first and last names, ID, age, medical record number, date of admission. Identification was considered adequate if at least two items were present, regardless of the bed number.

Illness severity (I in I-PASS): during the handoff, it was required to clarify whether the patient was stable, required control or was unstable.

Patient summary ( $P$ in I-PASS): it was required to include diagnosis, date of admission, current condition, history, critical events and complications, lines, drainages, tubes, other devices, current status, latest clinical examinations, and medication list.

Action list ( $A$ in I-PASS): it was required to include the actions to be taken and the party responsible for them.
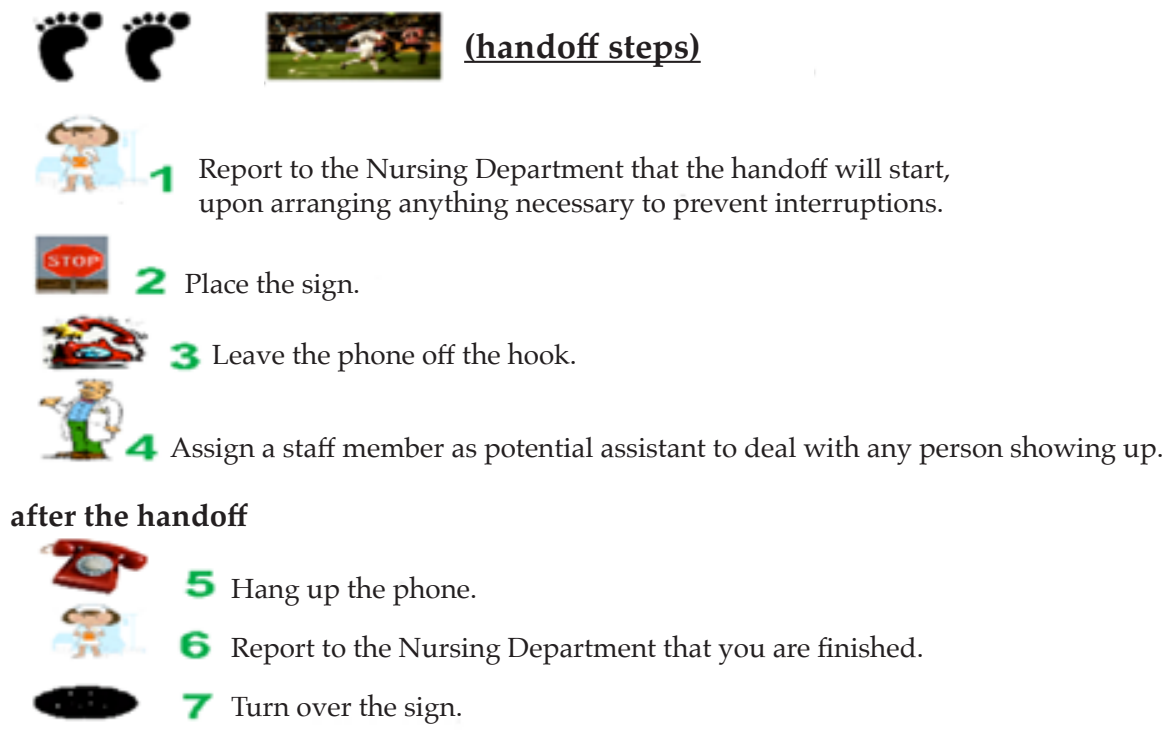
Situation ( $S$ in I-PASS): it was required to include contingency planning (what may occur) and the actions necessary to address them (what to do or who to ask).

Synthesis by the receiver (second $S$ in I-PASS): the person receiving the handoff was required to offer a synthesis about the patient.

Distractions or interruptions, together with the duration of each patient handoff (in seconds), were recorded. A form was developed to improve the written handoff. It included the I-PASS points to be completed for each patient (Figure 4).

\section{Statistical analysis}

Data were collected in an Excel database. Continuous outcome measures were estimated as mean and standard deviation or as median and interquartile range, based on their distribution. Categorical outcome measures were estimated as number and percentage. Continuous outcome measures were compared using an unpaired Student's $t$ test for parametric outcome measures and the Mann-Whitney $U$ test for non-parametric ones; categorical outcome measures were analyzed using the $\chi^{2}$ test. A value of $p<0.05$ was considered statistically significant. Data were analyzed using the Stata/IC 13.0 software for Mac (StataCorp LP).

\section{Ethical considerations}

The Institutional Ethics Committee approved the study and recommended its implementation for the training of all health care providers at the facility.

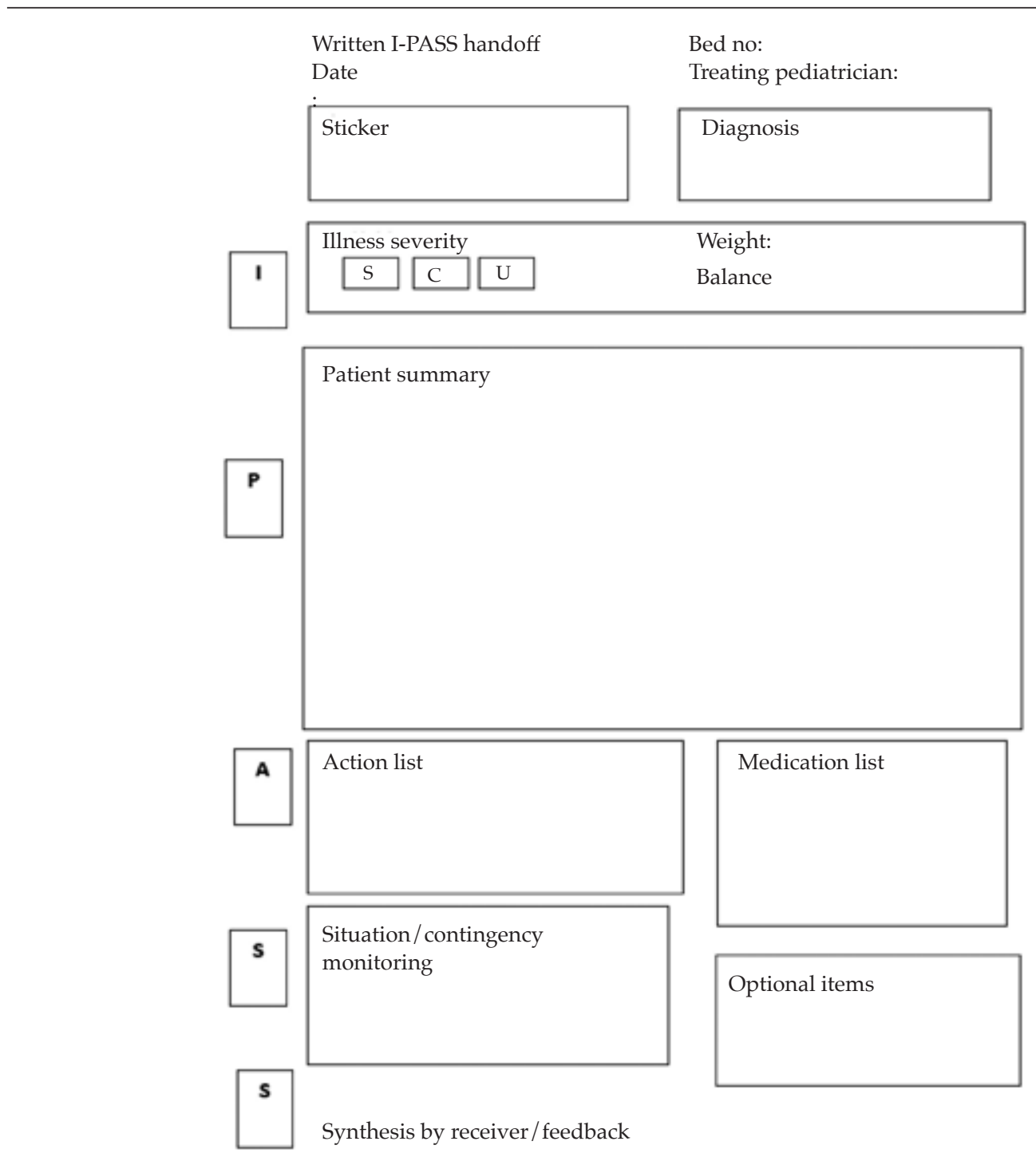




\section{RESULTS}

A total of 158 and 124 pre-intervention and post-intervention assessments were done, respectively. The comparison showed a significant improvement in the following: patient identification, disease relevance, personal history, medication, date of admission, situations and contingency planning, and synthesis by the receiver. As an exception, the disease summary was observed to be adequate in both periods.

No differences were noted in the handoff duration before the intervention, 199 seconds (174; 225), and after it, 210 seconds (190; 230), $p=0.523$. Interruptions during the handoff decreased significantly from $41 \%$ to $14 \%$ (Table 1).

\section{DISCUSSION}

Our study showed a clear improvement in the handoff process among physicians from a Department of Pediatrics, based on the implementation of the structured handoff I-PASS mnemonic. The intervention helped to improve key data transmission, both verbal and written. Compliance was above $70 \%$ in all aspects related to handoffs, with a clear reduction of interruptions and no changes in the time required to transfer information for each patient handoff.

Actions aimed at avoiding interruptions during handoff were greatly useful. Establishing an appropriate setting allowed to prioritize the handoff process and bring relevance back to both information transmission and the receiver's responsibility. Such improvement was consistent with what Starmer had observed at two units of the Children's Hospital of Boston, ${ }^{7}$ where a private and quiet setting improved verbal handoffs.

A focus on an adequate patient identification helps to prevent the usual errors caused by using only the patient's bed number or diagnosis and / or the first or last names. ${ }^{9}$ Describing the patient's severity at the beginning of the handoff helps to establish a common mental model. The patient summary was useful to better clarify their personal history, date of admission, and medication list, which provided the receiver a more comprehensive outlook. The other items also showed a very good performance in both phases. It is worth noting that there was an excessive load of ancillary testing data to the detriment of a discussion about diagnosis or management strategies.

It was also possible to establish the structure of actions or behaviors that the handoff receiver had to perform. The usefulness of checklists has been demonstrated in the field of aviation, architecture, economics, and medicine. They reduce errors and promote team integration among participants. ${ }^{10,11}$

Similarly to what Starmer et al., described originally, implementing the I-PASS mnemonic did not prolong handoff duration. The overall compliance with the mnemonic was close to $70 \%$,

TABLE 1. Compared observation of handoff process in each stage of the study

\begin{tabular}{lccc}
\hline & $\begin{array}{c}\text { Pre-intervention } \\
\text { (n= 158) }\end{array}$ & $\begin{array}{c}\text { Post-intervention } \\
\text { (n= 124) }\end{array}$ & $p$ \\
\hline Duration & $199(174 ; 225)$ & $210(190 ; 230)$ & 0.523 \\
Identification & $58.8 \%$ & $85.7 \%$ & $<0.0001$ \\
Interruption & $45 \%$ & $15.8 \%$ & $<0.0001$ \\
Disease relevance & $64.4 \%$ & $91.8 \%$ & $<0.0001$ \\
Diagnosis & $92.8 \%$ & $97.6 \%$ & 0.067 \\
Current condition & $81.2 \%$ & $92.1 \%$ & 0.009 \\
Personal history & $59.8 \%$ & $83.6 \%$ & $<0.0001$ \\
Complication & $70.1 \%$ & $81.8 \%$ & 0.028 \\
Lines/drainages & $75.9 \%$ & $82.8 \%$ & 0.174 \\
Current status & $98.7 \%$ & $100 \%$ & 0.198 \\
Tests & $79.7 \%$ & $89.4 \%$ & 0.03 \\
Medication & $77.2 \%$ & $97.6 \%$ & $<0.0001$ \\
Date of admission & $64.6 \%$ & $94.3 \%$ & $<0.0001$ \\
Behavior & $80.5 \%$ & $96 \%$ & $<0.0001$ \\
Responsible party & $63.4 \%$ & $87.2 \%$ & $<0.0001$ \\
Contingency situations & $51.7 \%$ & $81.7 \%$ & $<0.0001$ \\
Contingency planning & $47.9 \%$ & $80.9 \%$ & $<0.0001$ \\
Synthesis & $32.2 \%$ & $73.5 \%$ & $<0.0001$ \\
\hline
\end{tabular}


similar to the original study. ${ }^{8}$

It was also possible to implement a written computerized handoff document. This prevented errors due to illegibility and, at the same time, reduced adverse events, improved information contents, and facilitated updates. ${ }^{12}$

One of the strengths of this study was that observations were done every day and at the different handoff times. In addition, the I-PASS mnemonic was introduced in routine practice, for every handoff. A weakness of this study was the lack of determination of errors and adverse events attributed to a poor information and responsibility handoff. Although the study was conducted at a single site and in the pediatric area, it served as a pilot test for tool adaptation and effect size estimation in our setting.

To conclude, the I-PASS tool was adapted to Spanish and implemented at a health care facility, and demonstrated improvements in the handoff communication process, without prolonging its duration. Larger studies are required to broaden its implementation, but these results are highly promising for patient safety in Argentina.

\section{REFERENCES}

1. WatzlawickP, Bavelas JB, Jackson DD. Marco de Referencia. In: Watzlawick P, Bavelas JB, Jackson DD. Teoría de la comunicación humana. Barcelona: Herder; 2015.Págs.21-48.

2. Nasca TJ, Day SH, Amis ES, ACGME Duty Hour Task Force. The new recommendations on duty hours from the ACGME Task Force. N Engl J Med. 2010; 363(2):e3.

3. DeRienzo CM, Frush K, Barfield ME, Gopwani PR, et al. Handoffs in the era of duty hours reform: a focused review and strategy to address changes in the Acreditation Council for Graduate Medical Education Common Program Requirements. Acad Med. 2012; 87(4):403-10.

4. The Joint Commission. Goal 2: Improve the effectiveness of communication among caregivers. In Improving America's Hospital. The Joint Commission's Annual Report on Quality and Safety 2007. November 2007:34-5. [Accessed on: November 21 $\left.1^{\text {st }}, 2016\right]$. Available at: https://www. jointcommission.org/assets / 1/6/2007_Annual_Report. pdf.

5. Fryman C, Hamo C, Raghavan S, Goolsarran N. A Quality Improvement Approach to Standardization and Sustainability of the Hand-off Process. BMJ Qual Improv Rep. 2017; 6(1):u222156.w8291.

6. Horwitz LI, Krumholz HM, Green ML, Huot SJ. Transfers of PatientCareBetween HouseStaffonInternal MedicineWards: a national survey. Arch Intern Med. 2006; 166(11):1173-7.

7. Starmer AJ, Sectish TC, Simon DW, Keohane C, et al. Rates of medical errors and preventable adverse events among hospitalized children following implementation of a resident handoff bundle. JAMA. 2013;310(21):2262-70.

8. Starmer AJ, Spector ND, Srivastava R, West DC, et al. Changes in Medical Errors after Implementation of a Handoff Program. N Engl J Med. 2014; 371(19):1803-12.

9. Centro Colaborador de la OMS sobre Soluciones para la Seguridad del Paciente: Ayuda dememoria. 2007. [Internet]. [Accessed on: April 9th, 2019]. Available at: https:// www.who.int/patientsafety/ solutions / patientsafety / PatientSolutionsSPANISH.pdf?ua=1 www.ncbi.nlm.nih. gov/pubmed / 25372088 .

10. Haynes AB, Weiser TG, Berry WR, Lipsitz SR, et al. A SurgicalSafety Checklist to Reduce Morbidity and Mortality in a Global Population. N Engl J Med. 2009; 360(5):491-9.

11. Gawande AA. The Checklist Manifesto: How to Get Things Right. New York: Metropolitan Books; 2009.

12. Gakhar B, Spencer AL. Using direct observation, formal evaluation, and an interactive curriculum to improve the sign-out practices of internal medicine interns. Acad Med. 2010; 85(7):1182-8. 